This item was submitted to Loughborough's Research Repository by the author.

Items in Figshare are protected by copyright, with all rights reserved, unless otherwise indicated.

\title{
Animal perception in gravel-bed rivers: scales of sensing and environmental controls on sensory information
}

PLEASE CITE THE PUBLISHED VERSION

http://dx.doi.org/10.1139/cjfas-2013-0474

\section{PUBLISHER}

NRC Research Press (Canadian Science Publishing) / (C) The Authors

\section{VERSION}

AM (Accepted Manuscript)

\section{PUBLISHER STATEMENT}

This work is made available according to the conditions of the Creative Commons Attribution-NonCommercialNoDerivatives 4.0 International (CC BY-NC-ND 4.0) licence. Full details of this licence are available at: https://creativecommons.org/licenses/by-nc-nd/4.0/

\section{LICENCE}

CC BY-NC-ND 4.0

\section{REPOSITORY RECORD}

Johnson, Matthew F., and Stephen P. Rice. 2019. "Animal Perception in Gravel-bed Rivers: Scales of Sensing and Environmental Controls on Sensory Information”. figshare. https://hdl.handle.net/2134/16420. 
Animal perception in gravel-bed rivers: Scales of sensing and environmental controls on sensory information.

Matthew F Johnson ${ }^{1}$, Stephen P. Rice ${ }^{1}$

${ }^{1}$ Department of Geography, Loughborough University, Loughborough, Leicestershire, LE11 3TU, UK

Corresponding author: M.F.Johnson@lboro.ac.uk 


\begin{abstract}
Animals make decisions based on the sensory information that they obtain from the environment and other organisms within that environment. This information is transported, transmitted, masked and filtered by fluvial factors and processes, such as relative roughness and turbulent flow. By interpreting the resultant signals, animals decide on the suitability of habitat and their reaction to other organisms. Whilst a great deal is known about the sensory biology of animals, only limited attention has been paid to the environmental controls on the propagation of sensory information within rivers. Here, the potential transport mechanisms and masking processes of the sensory information used by animals in gravel-bed rivers are assessed by considering how the physical nature of sensory signals are affected by river hydromorphology. In addition, the physical processes that animals have the potential to directly perceive are discussed. Understanding the environmental phenomena that animals directly perceive will substantially improve understanding of what controls animals distributions; shifting emphasis from identifying correlations between biotic and abiotic factors to a better appreciation of causation, with benefits for successful management.
\end{abstract}

Keywords: Ecohydraulics; Sensory ecology; River; Bioacoustics; Turbulent flow; 


\section{Introduction to sensory perception}

The conservation and management of animals requires an understanding of their habitat needs. Equally, environmental processes that repulse animals need to be identified in order to limit potentially negative anthropogenic impacts on animal movement and distribution. In river ecology, there is a tendency to rely on correlative techniques that relate the spatial and temporal distribution of animals to dominant environmental conditions. Although such an approach can be an effective tool, there are two key disadvantages. First, correlation does not equal causality, which is particularly true in rivers where many environmental characteristics covary with hydrodynamic parameters and distance downstream. As a result, correlations between animal distributions and environmental parameters do not necessarily mean that the two are related, but rather that the two are related to any number of covarying parameters (also see Lancaster and Downes 2010). The second issue is that environmental conditions that are used to explain animal distributions tend to be selected, at least partially, based on methodological convenience rather than an assessment of their significance to animals or an assessment of the scale at which an environmental process is of most relevance to an organism (Rice et al. 2010). For example, the distribution of benthic animals in rivers is often related to temporally and spatially averaged flow measures, even though the distribution and behaviour of benthic organisms are almost certainly related to nearinstantaneous hydraulic measures in the near-bed region, not average conditions in the flow field above the bed (Lacey et al. 2012; Wilkes et al. 2013).

Aquatic animals have an arsenal of senses capable of obtaining detailed information about their environment and other organisms via visual, electrical, chemical, hydrodynamic, vibrational and acoustic pathways (see reviews in Pitcher 1992; Bleckmann 1994; Brönmark and Hansson 2000). The organs animals use to receive sensory information are extremely diverse and the subject of a large biological literature. It is only possible to provide a brief overview here (see extended reviews in Collin and Marshall 2003; Lancaster and Downes, 2013). Fish and insects detect light using organs ranging in complexity from eyes that can 
generate detailed images to relatively simple ocelli that only record the presence or absence of light. Many fish are predominantly visual and consequently have sophisticated eyes that are able to generate images (Douglas et al. 1990). Unlike most fish, the visual organs of many invertebrates are unlikely to form images that the animal can recognise and respond to, but are instead likely to be used to detect motion by identifying changes in light patterns (Lancaster and Downes, 2013). Polarized light may be of particular importance to aquatic invertebrates and is known to be key in the navigation and habitat selection of terrestrial insect stages (see review in Lancaster and Downes, 2013).

Arthropods and some mammals (seal whiskers; Dehnhardt et al. 1998) use sensory hair-like structures to detect hydrodynamic phenomena. Mechanosensory hairs are diverse in morphology and abundance and form a dispersed sensor array over the body of insects and crustaceans (review in Bleckmann 1994). The deflection of mechanosensory hairs permits individuals to gain information about the hydrodynamic environment, body movements or touch. Relatively little work has been undertaken on other invertebrate groups but potential hydrodynamic receptors have been found in annelid worms, flatworms, gastropods and bivalves (Büdelmann 1989). In addition, crustaceans and molluscs have a statocyst; a chamber within which there is a mineralised mass that, due to inertia, contacts sensory hairs when it is perturbed, aiding in the detection of vibrations, body movements and body accelerations. Fish and amphibians sense hydrodynamic phenomena with neuromasts along their lateral line, which also contain a hair-like structure that is deflected by water movement relative to the body (Bleckmann et al. 2003). Fish can use their lateral line to generate mental maps of the amplitude and direction of flow along their body (Plachta et al. 2003). At least some insects are able to detect water pressure using mechanoreceptor systems and some fish have specialised gas-filled chambers that can detect changing water pressure (Thorp and Crisp 1947). 
Acoustic stimuli consist of molecular particle displacements and associated pressure waves (Bass and Clark 2003). Animals that can detect both particle and pressure components of acoustic stimuli are more sensitive to sounds than those that only detect the particlemovement component, which includes all invertebrates (e.g. Popper et al. 2003; Amoser and Ladich 2005). Acoustic and hydrodynamic stimuli are similar, but there are key differences. For example, acoustic stimuli travel at the speed of sound (approximately $343 \mathrm{~m} \mathrm{~s}^{-1}$ in water) and are, consequently, unaffected by flow velocity or direction (Urick 1983). In contrast, hydrodynamic phenomena travel at a speed approximately similar to the flow velocity and are affected by flow direction.

Fish and invertebrates use chemoreceptors to detect chemicals transmitted through environments (smells; olfaction) and chemicals on objects (tastes; gustation). In insects, crustaceans and many other invertebrates, chemoreceptors are hair-like structures, similar to mechanoreceptors, which allow animals to gain detailed information about the odour source (Derby and Atema 1988; Koehl 2006). For example, even neurologically simple organisms such as flatworms (Dugesia dorotocephala) can learn to recognise fish odour as an indication of risk after one exposure to fish odour simultaneously with crushed-up conspecific individuals (i.e. other flatworms) (Wisenden and Millard 2001). In fish, chemoreceptors are usually located in the mouth and gills, but can be present on external surfaces, such as on the barbels of some cyprinids (Hansen and Reutter 2004). In chemical ecology, sensory information is divided into signals and cues. Sensory signals are sent intentionally to communicate with other organisms; for example, to attract a mate. Sensory cues are sent inadvertently by other organisms or as a product of abiotic processes (Webster and Weissburg 2009).

\section{Perspective aims}

This article focuses on two important aspects of sensory ecology that are of relevance to understanding animal distributions in rivers. The first is that the environment exerts a control 
on what animals can perceive, both by adding sensory 'noise' and by directly impeding the availability of sensory signals. These effects have the potential to mask important signals and cues. For example, turbidity in a river may mask the sight of prey organisms and the noise associated with flowing water may mask the sounds of an approaching predator. Consequently, physical processes can mediate interactions among animals by exerting a control on the pathway and transmission of sensory information. The transmission of signals and cues is as important as the biology of sensory organs for understanding the communication of animals in lotic systems (Figure 1). However, relatively little attention has been paid to how abiotic factors within rivers affect sensory information.

The second important aspect is that animals select suitable habitat, in part, by interpreting environmental information they obtain via sensory pathways. Therefore, understanding the environmental phenomena that aquatic animals can sense will provide information about the processes that attract and repulse animals. Such information is important for understanding why animals are distributed as they are and will help in identifying the underlying causes of a particular habitat preference, that correlative approaches can only hint at. Knowledge about sensory perception is already used to manage animal distributions in rivers, including the manipulation of fish movements through managed stretches (see review in Kemp et al. 2012) and in attempts to control invasive and pest species (Witzgall et al. 2010), such as signal crayfish in British rivers (Stebbing et al. 2004).

Although sensory ecology is a large and long-established field of biological research, most work on aquatic sensory perception has taken place in marine settings. Relatively little attention has been paid to fluvial environments and, in particular, the role of physical factors and processes in affecting the transmission of signals and cues, or animal responses to environmental cues. This Perspective focuses on the environmental controls on animal perception in shallow, coarse-bedded rivers, which are common globally, especially in 
montane and upland valleys and mountain forelands (Church, 2012), and has three specific aims:

1) To explain how some characteristics of gravel-bed rivers affect the propagation of sensory information.

2) To review how aquatic animals sense their surroundings and to explore the type and scale of physical processes that animals are likely to be able to directly perceive in rivers.

3) To suggest how best to incorporate sensory perception into future research and the major challenges ahead.

\section{What are the environmental controls on the perceptibility of sensory information in gravel-bed rivers}

Most sensory information in rivers is received after propagating through a complex and changeable environment, capable of altering the concentration, time duration, structure and spatial extent of the original signal or cue. Here, a brief overview of the phenomena that affect the transmission and transport of sensory information in gravel-bed rivers is provided and compiled in Table 1. Much of the knowledge about the interactions between sensory information and aquatic environments comes from marine settings which are not good analogues for gravel-bed rivers. However, some information obtained in other aquatic systems can be related to shallow, coarse-bedded rivers to offer insight into the processes that may be of most significance in such rivers.

\subsection{Topography and relative submergence}

Bed topography in rivers is variable in time and space and can be characterised at a range of spatial scales. Montgomery and Buffington (1997) define seven distinct typologies of upland channels and relate their occurrence to catchment and reach-scale processes. In coarse-bedded rivers, the reach-scale topography is often characterised by alternating shallow and deep regions of flow, termed riffles and pools, which are also characterised by 
faster flows and coarser grain-sizes in riffles for the majority of the hydrograph. At steeper channel slopes, morphology tends to be characterised by step-pools, which are accumulations of large grains that span the channel, separated by pools of finer material (Buffington and Montgomery 1997). At smaller spatial scales, the bed topography is dominated by individual grains (i.e. $>$ median $\left.\left[D_{50}\right]\right)$ ). The topography of rivers exerts an important control on the flow regime by creating roughness that contributes to turbulence generation and the development of coherent flow structures, which affect velocity distributions (Buffin-Bélanger et al. 2006). As a consequence, river typologies based on relative submergence ( $h$, the ratio of water depth $Y$ to some characteristic grain diameter or moment of the bed elevation distribution $H$ ) are useful (e.g. Nikora et al. 2001). Most research on the sensory ecology of aquatic animals has come from marine and other deepwater, slow-flowing systems with low relative submergence. In gravel-bed rivers, water depth tends to be low relative to the roughness of the bed (e.g. $0.5<h<20$ ), creating a highly dynamic, complex hydrodynamic environment that provides many challenges to sensory perception that are not present in deep-water environments (Nikora, 2010).

The topography of the bed, including the presence of vegetation, affects the propagation of sound in fluvial environments. In marine systems sounds can propagate great distances but, in rivers with high relative submergence, sounds are repeatedly reflected off roughness elements, resulting in multiple propagation paths (Figure 2). This leads to considerable signal distortion and limits propagation distance (Hawkins and Myrberg 1983; Mann and Lobel 1997; Ladich and Bass 2003). In addition, wavelengths greater than four-times the flow depth attenuate rapidly, an occurrence known as the "cut off phenomenon" (Officer 1958; Tonolla et al. 2009). Consequently, the environment can act as a filter such that the propagation of sounds with long wavelengths is constrained in shallow waters (Urick 1983; Rogers and Cox 1988). For example, the goby Padogobius martensii emits sounds predominantly in the $80-200 \mathrm{~Hz}$ band, but frequencies below $750 \mathrm{~Hz}$ do not propagate in water with a depth less than $50 \mathrm{~cm}$ (Lugli et al. 1995; 2003). Consequently, Lugli and Fine 
(2003) working in shallow stony streams found that the courtship sound of $P$. martensii attenuated by $15-20 \mathrm{~dB}$ over distances of $20 \mathrm{~cm}$.

The position of the 'noise window', an acoustic feature which is a quiet area of the spectrum, between high and low frequency noises, is of potential significance to many animals in rivers (Wysocki et al. 2007; Tonolla et al. 2009; 2010). The noise window usually falls in the 100$300 \mathrm{~Hz}$ region and is dependent on environmental conditions, although the exact characteristics responsible for the position of this quiet window are unknown (Lugli and Fine 2003; Tonolla et al. 2010). For example, the quiet area of the spectrum was more defined in the main channel of the Danube in comparison to a shallow, cobble-bedded alpine stream (water depth $<0.5 \mathrm{~m}$ ) where fluctuations in energy content were greater (Wysocki et al. 2007). Interestingly, the noise window corresponds to the frequency range used by many fish for communication and its presence may therefore be a desirable quality for some animals (Crawford et al. 1997; Lugli and Fine 2003). Consequently, the presence of a noise window might be of importance in the selection of habitat by many fish.

The topography of fluvial environments also impacts the propagation of light. Whilst shallow water depths in gravel-bed rivers mean light will usually penetrate to the bed, the complex topography creates areas of deep shadow in the interstices between grains. Bedforms and large grains that protrude into the water column will also block the line of sight of animals with sensitive vision. Invertebrates do not form visual images so may be less affected by the limitations on the propagation of light by complex topography. However, light sensitive cells provide important information to invertebrates about the presence and movement of other organisms and, therefore, invertebrate perception will be affected by topographic constraints on light availability.

Given the topographic complexity of rivers, some areas may be more suited to particular sensory pathways in comparison to others. For example, acoustic phenomena may not 
provide useful information to animals in shallow flows over coarse substrates where sound propagation is limited. In contrast, deep pools may favour acoustic senses. Similarly, where visual fields are limited by deep shadows or topography, reaction times to approaching predators may be reduced. In contrast, relatively flat expanses of fine sediment where there is no appreciable impact on light availability may benefit visually-orientated predators. Therefore, the topographic setting may act as an important control on the efficacy of sensory pathways, resulting in, for example, predator-prey interactions and food web linkages being partially dependent on the topographic setting.

\subsection{Plunging water and bubbles}

Plunging and jetting water is a relatively common phenomenon in upland river systems which are often characterised by stepped bed topography and associated, noisy hydraulic features. For example, the sharp transition from supercritical to subcritical flow as plunging water hits pooling water generates a hydraulic jump that substantially increases the air-water interface and entrains air into the flow (see Chanson 2009). The creation and bursting of air bubbles creates loud acoustic signals. As a result, rivers can be noisy environments (sound levels often $>100 \mathrm{~dB}$ ) with ubiquitous ambient noises that can severely mask the detection of important acoustic signals by animals (Wysocki and Ladich 2005; Scholz and Ladich 2006). Fish are differentially affected by acoustic masking. Masking reduces the ability of 'hearing-specialist' species to discern important acoustic cues from ambient noise to a greater degree than more 'hearing-generalist' species (Amoser and Ladich 2005). As a consequence, the hearing advantage of specialists over generalists is limited in noisy environments, such as fast-flowing rivers (Lugli and Fine 2007).

In addition, large quantities of air bubbles in the water column absorb and scatter sound (Urick 1983; Norton and Novarini 2001). Tonolla et al. (2009) identified a 'quiet zone' downstream from a hydraulic jump generated using an obstacle in a laboratory flume, which they hypothesised was due to the scattering of sound by bubbles from the jump. However, it 
is known that low frequency sounds are relatively unaffected by scattering and absorption in comparison to higher frequencies. Consequently, the presence of bubbles may act to filter acoustic signals in rivers. Measurements in shallow, stony streams (Stirone and Sercio Rivers, Italy) identified that most of the low-frequency noise generated underwater by a waterfall was lost within $2 \mathrm{~m}$ of the fall (Lugli and Fine 2003). The ability of animals to utilise acoustic features, such as quiet zones, is currently unknown, but such areas could be important to animals by allowing them to close in on prey without being heard, minimising or masking the sounds that might forewarn of an approaching predator. In such situations, reaction times may be reduced and animals might have to rely on other senses to locate prey or predators.

\subsection{Turbidity, suspended sediment and water clarity}

The presence of organic and inorganic sediment in the water column limits light penetration and thus limits the utility of vision for organisms that inhabit turbid waters. Light is attenuated as it travels through the water column because of scattering and absorption of photons (Kirk 1994). Although light is attenuated in clear water, light attenuation increases systematically as suspended sediment concentration increases (Walmsley et al. 1980; Lloyd et al. 1987, Davies-Colley and Smith 2001). For example, Davies-Colley and Close (1990) studied the visual clarity and apparent colour of 96 rivers in New Zealand under base-flow conditions and found that the scattering and absorption of light by suspended solids accounted for an average of $87 \%$ of the light attenuation. The optical impact of suspended sediment is dependent on the size, shape and composition of the particles, in addition to their quantity. Particles larger than the wavelength of light $(0.4-0.7 \mu \mathrm{m})$ attenuate twice the light impinging on their cross-sectional area (van de Hulst 1957). Consequently, the cross-sectional area of particles in suspension is an important control on light attenuation. The composition of particles is also important as it primarily determines the refractive index of the particles. Some suspended particles also absorb light, for instance, humic substances absorb blue light and thus impart yellow colours to waters, whereas clear waters tend to be blue-green 
due to the differential absorption of particular light wavelengths (Kirk 1985). In general, large particles rapidly settle out of the water column and, consequently, those that dominate light attenuation tend to be $0.2-5 \mu \mathrm{m}$ for minerals and $1-20 \mu \mathrm{m}$ for organic particles (Kirk 1994).

Animals perceive only particular wavelengths of light and the spectral capabilities of the vision of some animals, including many fish, is related to water colour (Anthony 1981; Lythgoe 1988; Losey et al. 2005). For example, stickleback populations have been found to be tuned to the colour of the environment from which they came, with those from red-shifted turbid lakes being most sensitive to red wavelengths and those from clear-lakes being most sensitive to blue (McDonald et al. 1995; McDonald and Hawryshyn 1995). Some aquatic invertebrates prefer dark substrates over light coloured substrates (Clifford et al. 1989; Tikkanen et al. 2000). Insects respond to wavelengths from around $350 \mathrm{~nm}$ (UV) to $700 \mathrm{~nm}$ (red) with maximal absorption at approximately $530 \mathrm{~nm}$ (green); however, relatively few studies exist that focus on the aquatic stage of insects. The taxonomic similarity between some terrestrial and aquatic species of insect makes it is possible to gain some information about the visual capabilities of aquatic insects. Also, studies of the adult, terrestrial stage of insects can provide important information about the larval, aquatic stage. For example, terrestrial insects are known to utilise polarised light and to respond to the spectral quality of light (see Briscoe and Chittka, 2001), suggesting that the filtering of light spectra by the environment could be of significance to at least some aquatic invertebrates. For example, it is possible that tannins from vegetation decay or ochre from ferrous iron that shift colour spectra could change ecosystem processes by altering the functionality of vision in some animals.

Suspended sediment loads typically increase longitudinally in rivers, reflecting increased cumulative upstream inputs and discharge with distance downstream. Consequently, many coarse-bedded headward streams are relatively clear in comparison to large lowland rivers 
or estuaries. However, turbidity levels can fluctuate greatly at a range of spatial and temporal scales so at times coarse-grained streams can be highly turbid. In particular, turbidity changes in response to the availability of fine sediment and the river's ability to transport it and therefore with the hydrograph, the seasonality of instream vegetation, land-use variations and the incidence of river bank or valley slope mass movement events.

Consequently, the sensory capability of predominantly visual animals may change seasonally as turbidity levels fluctuate in response to annual hydrographs. High levels of turbidity not only attenuate light, but can also mask objects and reduce the contrast between an object and its background, which may, for example, affect feeding ability (e.g. Crowl 1989; Miner and Stein 1996; Turesson and Brönmark 2007). Mate selection can also be affected by increased turbidity, for example, male three-spine sticklebacks (Gasterosteus aculeatus) have to court significantly more in turbid seawater in comparison to clear water in order to receive the same amount of interest from females (Engström-Öst and Candolin 2006). Some fish actively avoid areas of high turbidity (Sigler et al. 1984). For example, in laboratory studies, Coho salmon (Oncorhynchus kisutch) acclimatised to clear water showed significant avoidance of water with turbidity greater than 70 nephelometric turbidity units (NTU) (Bisson and Bilby 1982).

Turbidity is like fog in terrestrial environments, reducing the visibility of objects at a longdistance, but having little effect on the detection of close objects (Utne-Palm 2002). Increased turbidity is more disruptive to animals that detect prey from a long-distance in contrast to those that detect prey at short distances (Chesney 1989; Giske et al. 1994; Rowe and Dean 1998). Therefore, turbidity affects animals differently depending on their visual ecology; and those animals that are not predominantly visual may be unaffected by changing turbidity levels, including many invertebrates, which dominate animal biomass in rivers. However, because fish are important predators the light regime in rivers and, consequently, 
suspended sediment dynamics, is an important structuring characteristic of the ecological community. It may also be that seasonal differences in turbidity level result in seasonality in the efficacy of vision. Therefore, some species interactions may be seasonal, for example, with visual predation more effective at low turbidity levels, but other sensory pathways, such as hearing, more important when turbidity levels are high.

\subsection{Flow direction and turbulence}

Because the net flow direction in rivers is downstream, waterborne signals, such as chemical and hydrodynamic stimuli, are usually only perceived when originating from upstream. Evidence for the importance of the downstream transport of signals includes the fact that fish are widely known to hunt in an upstream direction, at least partially because they can only smell upstream prey and the prey cannot smell the downstream predator. Baited traps have also been shown to only attract animals from down-current (Busdosh et al. 1982). More complex ecological interactions are also mediated by the flow direction. Bergman et al. (2006) found that when crayfish (Orconectes rusticus) fought in still water, they positioned themselves randomly, which was in contrast to aggressive interactions under flowing water conditions where individuals released more urine (used as a signal to demonstrate dominance) when positioned upstream of a competitor, in an attempt to maximise transmission of chemical cues.

When chemical signals or cues are transported distances greater than $1 \mathrm{~mm}$ the dispersal of chemicals is dominated by turbulent mixing. In all rivers, the flow is always highly turbulent (typically $\operatorname{Re}>10^{5}$ ). Although turbulence is seemingly random and frequently treated as a stochastic process, common phenomena can be isolated in turbulent flows. For example, turbulence has 3-dimensionality, is intermittent in time and space over a range of scales and has rotationality (Nikora 2010). These observations have led to the study of turbulence in a more deterministic way and the identification of characteristic coherent flow structures (CFS) in gravel-bed rivers, including eddies of various scales and types that are distributed partly 
as a function of relative submergence and flow Reynolds number (see Ashworth et al. 1996; Roy et al. 2004). It is CFS that entrain, transport and mix chemical signals in rivers, resulting in chemical plumes becoming intermittent and concentrated into spatially and temporally discrete volumes that have been called 'parcels' 'streets', 'filaments' or 'vortices' of odour, separated by odourless water (Atema et al. 1991; Zimmer and Butman 2000; Webster and Weissburg 2009). These odour vortices create trails that can be tracked by animals to their source on the scale of centimetres to metres. For instance, various scavengers have been found to track odour vortices to decaying animal matter (Busdosh et al. 1982; Tamburri and Barry 1999).

Whilst plumes of odour have been identified, quantitative study remains relatively limited, and is dominated by studies in marine settings where water is deep relative to the substrate roughness (see Webster and Weissburg 2009 and references therein). In rivers, relevant work has been undertaken on the dispersion and mixing of chemical plumes for other purposes, such as the dispersion of plumes of effluent (Roberts and Webster 2002). This research can inform the expected transport and dispersion rates of chemical information between organisms, although the viscosity of the chemical will exert an important control and should therefore be considered when looking for an analogue. Minimal research has been undertaken to determine the ability of riverine animals to track chemical signals. Exceptions include the work of Wolf et al. (2009) who measured larger fluctuations in a surrogate chemical signal in gravel-bedded areas of a river than in sand-bedded reaches, due to the greater turbulence generation over coarser substrates. Moore and Grills (1999) also found that crayfish (Orconectes rusticus) located food quicker in streams with cobble beds rather than those with sand substrates and suggested that this was because of increased turbulent mixing and, consequently, wider propagation of the signal. However there is not consistent support for this hypothesis and walking speed can also be directly affected by bed roughness due to the challenge of navigating complex topography. There is evidence that some mixing is beneficial to tracking, for example, the predatory success of 
blue crabs, a marine species, was greater at free-stream flow speeds of $1 \mathrm{~cm} \mathrm{~s}^{-1}$ in comparison to still-water (Weissburg and Zimmer-Faust 1993; 1994). However, it is possible that plume tracking is ineffective in many river settings due to the rapid dispersion of chemical plumes.

Turbulence also masks hydrodynamic signals. As a result, the distance over which a hydrodynamic event, such as a wake, can be tracked is likely to be limited in rivers and other turbulent environments as ambient turbulence homogenises flow fields and eradicates any biotic hydrodynamic cue (Figure 3). The majority of hydrodynamic stimuli used in previous research are either artificial (i.e. water jets, vibrating spheres) or were employed in still-water experiments or deep marine environments, characterised by weak ambient flows relative to wake flows. Consequently, the extent to which animals in rivers can utilise hydrodynamic stimuli to track other organisms is poorly understood, although many animals that reside in rivers have the potential to detect hydrodynamic signals. For example, larvae of the stonefly Kogotus modestus can discriminate the swimming pattern of prey mayfly larvae (Baetis bieaudatus) from non-prey mayfly larvae (Ephemerella infrequens), even when the hydrodynamic signature is generated by a plastic model in the absence of chemical or visual signals (Peckarsky and Wilcox 1989). Hoover and Richardson (2010) also found that a simulated predator, creating visual and hydrodynamic cues, initiated an escape response in three mayfly species (Ameletus sp., Baetis sp. and Epeorus sp.). This implies that there is a specific signature to biological flows that allows some animals, at least, to identify and differentiate prey, competitors or predators from the ambient, abiotic turbulent environment. The extent of this ability and the nature of biotic hydrodynamic signatures is unknown, but it is likely to be associated with irregular, high amplitude and high magnitude components of wakes associated with the moving appendages of living animals. 
The velocity and turbulence of flow, and hence the propagation and masking of chemical and hydrodynamic phenomena, is dependent on microhabitat. For example, animals living in the hyporheic zone, where turbulence intensity and velocity are relatively low and flow paths are constrained, chemical and hydrodynamic phenomenon may provide more information in comparison to species living on the exposed surface of rocks where masking and mixing processes will rapidly disperse and alter the structure of hydrodynamic and chemical signals and cues. The rapid dispersion of chemicals may be beneficial to some organisms if the signal indicates the presence of conspecifics or predators, but may also reduce reaction times or the ability to accurately locate the odour source. Consequently, the ability of animals to interpret and respond to waterborne sensory information and, consequently, the ability of animals to communicate and respond to each other with scents, is dependent on the environmental conditions.

\section{Which environmental processes can animals can sense in gravel-bed rivers?}

Whereas the previous section focused on how environmental conditions mask, filter and propagate sensory information, this section focuses on the environmental phenomena that animals can directly perceive. Animals make decisions about the suitability of fluvial environments at least partially based on their perception of sensory information they receive. As such, a better understanding of the phenomena that contribute to animals' decisions about where to stay or whether to move would improve our understanding of the causal links between animals and environments.

\subsection{Perception of topography and relative submergence}

Whilst there is much work on animals utilising topographic features or fluvial bedforms, such as fish holding in pools or invertebrates exploiting microtopography to avoid entrainment by the flow (i.e. Rice et al. 2008), there is relatively little work on the specific sensory information that informs animals about the geometry or characteristics of topographic features in rivers. Some animals that swim in the water column have the potential to see the 
topography. However, animals in turbid water, benthic organisms that live between grains, and most invertebrates that cannot form images, cannot visually assess topography. Instead, other senses must be employed. In marine environments, many fish species are able to gain information about currents and coastlines by detecting sounds generated by the interaction of water flows and topography (Lagardére et al. 1994; Popper et al. 2003) and marine fish orientate to the sounds of suitable habitat (Tolimieri et al. 2000; Leis et al. 2003; Simpson et al. 2008). For example, in binary choice experiments, Tolimieri et al. (2004) found that damselfish larvae orientate towards ambient reef sounds and Leis et al. (2002) found damselfish and butterflyfish discriminate between reef sounds at distances up to $100 \mathrm{~m}$. Similar experiments have not been performed in rivers, but hydromorphological units (for example, riffles, pools and glides) have distinct sound characteristics such that some animals could potentially discriminate between fluvial habitats using acoustic cues (Wysocki et al. 2007; Tonolla et al. 2010).

The soundscape of a habitat is a combination of environmental sounds (geophony) and biological sounds (biophony) (Pijanowski et al. 2011). Therefore, soundscapes in rivers integrate many physical and biological processes, but are likely to be dominated by the hydraulic conditions. The noisiness of rivers is related to relative submergence, with low submergence related to noisy conditions and increased temporal variability across frequency bands (Tonolla et al. 2010). In addition, Lugli and Fine (2003) found rivers to be quiet places in areas where the water surface remained unbroken. It was only when the surface broke, with air bubbles entrained and subsequently collapsing, that ambient noises increased significantly in all frequencies (Lugli and Fine 2003). Soundscapes also vary over time due to changing abiotic conditions and biotic communities. For example, Amoser and Ladich (2010) recorded the ambient acoustic noises in a range of freshwater habitats throughout the year and found that sound pressure levels varied by up to $40 \mathrm{~dB}$ in the best hearing range of fish, but no clear seasonal pattern could be determined. 
Some animals may be able to use soundscapes to assess the changing spatial and temporal distribution of the relative submergence and flow conditions in rivers. For examples, fish may be able to discriminate riffles from pools, aiding navigation and the identification of suitable locations to forage in. It may also be possible for animals to determine relative flow levels from the soundscape generated which might allow some species to avoid high or low flow levels.

\subsection{Perception of habitat suitability using chemical signals}

The detection of chemical cues has been shown to be of great importance in the identification of habitat. Over large scales, chemical cues are thought to aid the homing of anadromous salmonid fishes back to their home stream. Studies demonstrate that salmon can follow the chemical signature from their home stream for many kilometres and can differentiate streams using chemical cues (Dittman and Quinn 1996). At much smaller scales, the process of larval settlement in benthic marine invertebrates is known to be controlled by chemical signals in conjunction with the hydrodynamic environment. Examples include the larvae of reef-building worms (Phragmatopoma lapidosa) that are induced to settle amongst adult aggregations by the smell of the cement secreted by adults during tube-building (Jensen and Morse 1984; Pawlik and Butman 1993). The settlement and oviposition of freshwater invertebrates may also be influenced by chemical signals; for example, ponddwelling Chaoborus species exhibited an ovipositing preference for fish-free water (Berendonk 1999) and oviposition by mosquitoes is related to a number of repellent and attractant chemicals (i.e. Van Dam and Walton, 2008; Reiskind et al. 2009). Therefore, the presence or absence of other animals and their scents can be used to differentiate between potentially suitable and unsuitable habitats. Chemicals that mark suitable habitat for invertebrates are likely to cover only small areas, yet will be widely dispersed in the water column. Consequently, it may be that chemicals do not provide a useful cue for invertebrate habitat selection but, instead, are more useful as broad indication of the biological community in the vicinity, including the presence of predators or conspecifics. When used for 
this purpose, the wide dispersal of chemical signals may become a benefit to some organisms.

\subsection{Perception of sediment transport}

Material coarser than $2 \mathrm{~mm}$ is typically transported as bedload in gravel-bed rivers, and this only occurs during periods of high flow. Benthic animals can be dislodged or damaged by moving bed material. When sediment transport occurs, even at low to moderate levels, the number of invertebrates found drifting in the water column increases greatly (Gibbins et al. 2007). However, river beds remain stocked with invertebrates post-flood, implying that many organisms can survive such events by actively or passively finding refuge (Lancaster and Hildrew 1993; Gjerløv et al. 2003; Death 2006). In addition, it is common for some invertebrates to be preferentially located in stable areas of substrate (Death 1996; Effenberger et al. 2006). For example, Matthaei et al. (2000) found that after a flood event invertebrate densities on stable stones exceeded pre-disturbance levels. Some insect larvae can actively control their drifting behaviour and the distances over which they drift by, for example, bursts of swimming (Fairchild and Holomuzki 2005; James et al. 2009; Oldmeadow et al. 2010). Consequently, to avoid damage invertebrate animals may also have the ability to identify stable locations as refugia from sediment transport or to actively drift from the bed when sediment transport begins. However, the sensory information that might flag that a grain as stable, or when a substrate will become mobile, is unclear.

Whilst some fish may be able to see moving bed material, many will need to respond to other cues, not least because increases in turbidity when the bed is mobile are likely to limit visual ability. Animals may identify that there is a danger of substrate mobilisation when flow velocities are high or may be able to sense when the bed is moving from vibrational and acoustic signals generated by grains knocking together. The sound of moving bed material has been successfully used to measure bedload transport rates with grain impacts creating loud, discrete, high frequency sounds (Rickenmann and McArdell 2007). Turbidity typically 
increases as fine sediment is made available during flood events, especially as coarser bed material is mobilised and subsurface stores of sediment are accessed. Turbidity might then be a key cue which indicates bed instability for visual animals.

Seismic information (vibrations) may provide cues about the onset of bed instability. Little is known about the use of vibrations in rivers, but many aquatic invertebrates are sensitive to these cues, and the terrestrial stage of many insects are known to use substrate born vibrations to communicate (see review in Lancaster and Downes, 2013). For example, caddisfly sense vibrations through their catch-nets which might signal entangled prey or other organic matter (Tachet 1977) and male mottled sculpin (Cottus bairdi) knock their head and body into the substrate, creating vibrations that can be detected $10 \mathrm{~cm}$ away by females and competitors (Whang and Janssen 1994). Janssen (1994) also demonstrated that mottled sculpin place their mandibles onto the substrate allowing them to detect the seismic vibrations generated by invertebrate prey. Therefore it is possible that animals could use seismic signals generated by grain impacts to detect and respond to bedload transport.

\subsection{Perception of the flow}

Fish locomotion and behaviour has been successfully related to turbulent flow structures, including von Kármán vortex streets (e.g. Liao et al. 2003; Enders et al. 2005). However, studies rarely account for the more heterogeneous and dynamic turbulent environment in rivers, which are likely to break up structures such as von Kármán streets under most conditions (see reviews in Lacey et al. 2012; Wilkes et al. 2013) and evidence for the importance of turbulence to fish distribution and behaviour is equivocal (i.e. Nikora et al. 2003; Enders et al. 2009). The distribution of fish in rivers has been linked to flow depth and velocity (e.g. Hughes and Dill, 1980) and such suitability assessments in varying degrees of sophistication (cf. Lamouroux et al. 2010) are the basis of almost all modelling of fish-flow relations. However, it is unknown whether fish are responding to the flow, or to correlated variables such as greater drifting food provision in faster flows or a darker environment in 
deep water. Therefore, a greater understanding of the specific hydrodynamic features that fish can perceive and how they use this information to interpret and navigate their environment would better inform which flow conditions are important to their locomotion, behaviour and distribution.

Behavioural studies have demonstrated that fish utilise hydrodynamic information in their avoidance of within channel structures, a fact that has allowed the manipulation of fish movements using artificial flows in fish-avoidance schemes (Haro et al. 1998; Kemp et al. 2006; Kemp and Williams 2009). Nestler et al. (2012) suggest that fish use flow deformations downstream of within-channel features to generate a 'hydrodynamic image' that allows them to navigate topographically complex environments. For example, behavioural studies with blind cave fish (Astyanax hubbsi) have demonstrated their ability to navigate obstacles from changing pressure distributions, despite their blindness (von Campenhausen et al. 1981; Abdel-Latif 1990; Sharma et al. 2009). Consequently, at least some species of fish appear able to use meso-scale (metres) hydrodynamic features to interpret their environment, in addition to fine-scale $(\mathrm{cm})$ turbulent bursts that may indicate the presence of prey or predators. Invertebrates also respond to hydrodynamic features (e.g. Hart et al. 1996). However, the ability of benthic invertebrate organisms to interpret larger scale features is unknown and is probably restricted by the potential of high levels of nearbed turbulence to mask relevant signals and cues.

Many animals use visual cues to orientate to surface waves and swim towards their source, including leeches that swim towards moving bars of light designed to replicate the optimal signature of waves (Dickenson and Lent 1984). Similarly, fishing spiders, back-swimmers, water striders and surface-feeding fish will move towards the centre of concentric surface waves, which may indicate prey dropping into the water (Bleckmann 1985; Bleckmann 1994). Animals have been shown to discriminate wave stimuli using the wave form, amplitude, frequency content, slew rate (amplitude increase with time), interval and duration. For 
example, leeches can require several seconds of continuous wave stimulation before beginning to swim, probably because insect-generated wave stimuli last much longer than most other wave types (Dickinson and Lent 1984). Fishing spiders use the curvature of waves to estimate the source distance, identified because distance determination is impaired when spiders are presented with linear waves (Bleckmann 1988).

Water movements in aquatic systems can provide a great deal of information about the environment and the presence of other animals. Consequently, many aquatic animals have sensitive hydrodynamic receptor systems that directly perceive fluid flow. The anatomical structure of these receptor systems has been the subject of extensive research (Tautz and Sandeman 1980; Coombs and Janssen 1989;Bleckmann, 1994), but the extent to which they are used to perceive fluvial environments remains largely unknown. For example, many fish have the sensory ability to make simultaneous velocity measurements at multiple points along their body, giving them the potential to obtain information such as the vorticity of wakes. However, little is known about the extent to which fish can interpret this information, although Chagnaud et al. (2006) showed that fish are sensitive to vortex-ring motions. By stimulating these organs, it is possible to establish the range of flows that can be sensed. For example, a neural response was found when the sensory hairs on crustaceans were stimulated by flows as slow as $0.006 \mathrm{~cm} \mathrm{~s}^{-1}$ (Wiese 1976; Bleckmann 1994).

\section{Future research and challenges}

\subsection{The importance of incorporating sensory information into the ecology of fluvial landscapes}

This Perspective highlights the unique complications associated with animal perception in rivers and the difficulty in applying information from other environments, including marine and lacustrine systems, to fluvial landscapes. It also makes a case that insights from sensory biology can help river scientists establish causal relationships between animals and their habitat, which can be situated within broader calls for sensory ecology to be better 
incorporated into conservation management and animal ecology (Lima and Zollner, 1996; Schmidt et al. 2010; Madliger, 2012). Finally, it proposes a key role for geomorphologists and hydraulicists who are in a position to offer key insights into the transport and masking of sensory information in rivers, which is critical to animal behaviour and distribution, yet understudied (Figure 4). Ideally, it will be inter-disciplinary teams of researchers who will progress understanding in this area.

The challenges, further detailed below, are daunting. However, in terrestrial environments, sensory ecology has already been successfully integrated with other disciplines to better understand animal activity, often in unforeseen ways. For example, Wrege et al. (2010) found that elephants in the Ghanaian forest became more nocturnal due to seismic vibrations caused by dynamite blasts associated with the oil industry. Wrege et al. (2010) noted that possible seismic effects were only investigated because previous studies showed that elephants can detect and respond to seismic vibrations (see review in O'ConnelRodwell 2007) and concluded that the nocturnalism would not have been identified through standard monitoring techniques. Sensory ecology has also been essential in untangling ecological and evolutionary 'traps', where animals incorrectly interpret their environment (see review in Schlaepfer et al. 2002). For example, sea turtle hatchlings are attracted to artificial inland light sources, but an understanding that turtles orientate in the ocean using shortwavelength light allowed a reduction in turtle mortality by replacing bulbs in coastal settlements with longer-wavelength alternatives (Witherington and Martin 2003).

\subsection{The need for information at relevant scales and how to obtain such information}

Incorporating the sensory perception of animals into our understanding of the distribution of animals in rivers will require novel experiments to be undertaken in flume and field environments. At present, there is a lack of information on what phenomena, and what scale of phenomena, animals can sense. Consequently, it is important to determine how animals respond behaviourally to particular phenomena, such as the sounds and vibrations that are 
characteristic of sediment transport, in isolation from other signals and cues. This will require the integration of detailed, current, hydraulic and geomorphic techniques, at scales relevant to organisms, with behavioural and sensory ecology.

Understanding the scale of processes that provide environmental information to animals is of particular importance. For example, the sensory hairs of crustaceans can number many thousands and are distributed across the whole body-length. The velocity threshold of hairs may be as low as $0.006 \mathrm{~cm} \mathrm{~s}^{-1}$ with each hair sampling at a rate of up to $150 \mathrm{~Hz}$ (Wiese 1976; Breithaupt and Tautz 1990). Therefore, crustaceans such as crayfish in rivers, may be able to gain detailed information about the turbulent characteristics of flow, and process substantially more than depth- and reach-averaged velocity information. It is also known that turbulent flow characteristics have little relationship to averaged measures, demonstrating that correlations between animal distributions and averaged flow parameters are unlikely to be causal, but more likely to reflect correlation between the flow and other environmental parameters. It is therefore important to relate animal distributions and activity to finer scale flow and roughness measurements in hydraulically complex environments (Hart et al. 1996; Biggs et al. 2005; Wilkes et al. 2013). Although there is increasing research focused on the distribution and activity of animals in turbulent hydrodynamic environments, these studies rarely consider how an animal perceives the flow or what it is specifically capable of perceiving, both of which would improve experimental design and, in turn, understanding of hydraulic habitat selection.

The sensory ability of an animal is used to define a perceptual range, defined as the distance from which an animal can perceive a feature in the landscape. Lima and Zollner (1996; page 132) describe the perceptual range as an animal's "informational window on to the greater landscape" and, consequently, all decisions made by the animal are dependent on its perceptual range. It is also interesting to consider the temporal scale of perception. For instance, a prey organism is under pressure to make virtually instantaneous decisions 
regarding whether a particular sensory signal or cue indicates the presence of an approaching predator in order to escape before being attacked. Information regarding both the spatial perceptual range of organisms and the temporal scale over which animals make decisions is necessary to fully understand their activity.

\subsection{Developing a deterministic view of animal-environment relationships}

Mean-based statistical relationships dominate modelling of animal distributions and environmental conditions despite the fact that these rarely reflect the complex and changeable relationships between animals and their environment (see Lancaster and Downes 2010). Such approaches are rarely used in other environments or branches of biology. Using correlative approaches without consideration of ecological interactions can lead to erroneous results not least because animal distributions usually reflect both ecological interactions and environmental processes and factors, which is not always fully recognised in rivers (see Palmer et al. 1997; Field of Dreams). Consequently, the location of an animal does not necessarily indicate a preference for the environmental conditions at that location as animals may not have a free choice of where to reside given the need for food and the threat of predation and competition. For example, Harrison et al. (2006) found signal crayfish juveniles predominately in riffles whereas adults were found in pools. Using correlative techniques this could be interpreted as a changing habitat preference with juveniles preferring shallow, coarse river-beds. However, Harrison et al. (2006) also established that both adults and juveniles prefer pool habitats but that juveniles are excluded from pools by the larger adults.

A first step towards developing deterministic relationships between aquatic animals and fluvial environmental processes may be to correlate the spatial and temporal distribution of animals to processes at a relevant scales rather than to gross environmental measures (Rice et al. 2010). In doing so, it will be important to recognise habitat units integrate many processes and their presence and morphology is correlated to many other factors making it 
difficult to isolate the specific phenomena that animals may utilise in making decisions. Also, particular environmental units, such as riffles, can be visually and morphologically similar between sites and rivers, but are likely to be formed and maintained by very different processes or different magnitudes of process. Consequently, relating animal presence/absence or activity to particular turbulent characteristics, light levels or acoustic spectra rather than to patches of particular sediment grain-size would be beneficial.

Relative submergence is of particular importance to sensory perception because it strongly affects the generation of turbulent structures that mix and mask chemical and hydrodynamic signals; it impacts the transmission of acoustic signals due to the cut-off phenomena and reflection off protruding surfaces; and it reduces the line of sight for visual animals. Because relative submergence is variable in both cross-stream and stream-wise directions due to the presence of bedforms and marginal bar forms, it may be particularly difficult to perceive other organisms in some parts of river systems. For example, the relatively noisy environment in a riffle, coupled with turbulent mixing and masking of water-borne cues, may make locating prey difficult. Alternatively, a deep pool which enables the propagation of sound and allows visual predators to view the bed, may make locating prey relatively easy. Therefore, biological interactions, particularly between predator and prey, are dependent on the environmental context and the constraints on perception with potential implications for the spatial structure of food webs.

The same is true at smaller scales where the microhabitat will exert a control on the sensory information available to animals. For example, invertebrates that burrow into patches of fine sediment rely on vibrational signals in the absence of other sensory information whereas animals that swim in the water column may have multiple sensory pathways available (e.g. hydrodynamic, visual, sound, chemical). Different microenvironments will also differently propagate and mask sensory information. An insect larvae living in the interstices between grains or in the hyporheic zone will experience limited light but more coherent hydrodynamic 
and chemical plumes because of reduced flow velocity and turbulent intensities. In comparison, an insect living on the exposed surface of a rock will be in a light environment, but with relatively high velocities and turbulent intensities mixing and masking chemical and hydrodynamic information. Therefore, microenvironmental context will determine the sensory information available to an animal and, as a consequence, its behaviour and interaction with other organisms.

\subsection{Integrating information across a range of scales}

Perhaps the biggest challenge to the incorporation of elements of sensory biology into fluvial ecology and hydromorphology is relating small-scale information about the experience and decision making of individual organisms to entire animal populations in river systems. Whilst this is a daunting challenge, incorporating information from differing scales is a commonly encountered issue in ecological and geomorphic research (e.g. Biggs et al. 2005; Rice et al. 2010) and there have been many successful attempts in other environments to relate smallscale sensory information to models of entire animal populations (i.e. Madliger 2012 and references therein). It is also a challenge well suited to modelling studies (e.g. see Martin et al. 2013).

There is also a need to integrate information at a range of temporal scales because fluvial environments are dynamic and the habitat preference of animals change with life-stage. In addition, the sensory ability of animals changes depending on the life-history stage (Huntingford 1993), physiology (Giorgi et al. 1988) and the learned-experience of individuals (Kieffer and Colgan 1992). Also, the highly dynamic nature of many of the processes that mask, filter and transport cues and signals in rivers could generate important temporal and spatial variability in the ability of animals to sense their surroundings.

In conclusion, the physical environment in rivers masks, filters and transmits sensory information, with implications for how animals perceive their environment and other animals 
within that environment. As a result the signal or cue received by an organism is likely to be substantially different from that originally generated, in terms of concentration, time duration and spatial extent. In addition, animals directly perceive their physical environment in order to make informed decisions about their location. However, little is known about which particular environmental phenomena generate cues that river fauna utilise and an improved understanding of this would help us to develop better causal links between organisms and their habitat and to unravel the relative roles of physical and biological factors. Integrating sensory biology and environmental science is an ambitious goal, not least because the progress made in terrestrial, lentic and marine environments cannot be easily applied in fluvial settings, especially relatively shallow, gravel-bed rivers. However, if the challenges detailed above are tackled, the resultant information will provide a deeper understanding of why animals are found where they are and, in the context of river management and conservation operations, what stimuli may be used to attract or repulse them to their benefit.

\section{Acknowledgements}

We are indebted to extremely helpful contributions from four encouraging reviewers who greatly improved the manuscript. Any failings remain our own.

\section{References:}

Abdel-Latif, H., Hassan, E.S. and von Campenhausen, C. 1990. Sensory performance of blind Mexican cave fish after destruction of the canal neuromasts. Naturwissenschaften 77: 237-239.

Amoser, S. and Ladich, F. 2010. Year-round variability of ambient noise in temperate freshwater habitats and its implications for fishes. Aquatic Sciences 72: 371-378.

Amoser, S. and Ladich, F. 2005. Are hearing sensitivities of freshwater fish adapted to the ambient noise in their habitats? Journal of Experimental Biology 208: 3533-3542. 
Ashworth, P., Bennett, S., Best, J.L. and McLelland, S. (eds) 1996. Coherent flow structures in open channels. John Wiley and Sons, UK

Atema, J. 1996. Eddy chemotaxis and odor landscapes: Exploration of nature with animal sensors. Biological Bulletin 191: 129-138.

Bass, A.H. and Clarke, C.W. 2003. The physical acoustics of underwater sound. In Acoustic Communication. Edited by Simmons, A.M., Popper, A.N. and Fay, R.R. Springer, New York, USA. pp. 15-64.

Berendonk, T.U. 1999. Influence of fish kairomones on the ovipositing behavior of Chaoborus imagines. Limnology and Oceanography 44: 454-458.

Bergman, D.A., Redman, C.N., Fero, K.C., Simon, J.L. and Moore, P.A. 2006. The impacts of flow on chemical communication strategies and fight dynamics of crayfish. Marine and Freshwater Behaviour and Physiology 39: 245-258.

Biggs, B.F.J., Nikora, V.I. and Snelder, T.H. 2005. Linking scales of flow variability to lotic ecosystem structure and function. River Research and Applications 21: 283-298.

Bisson, P.A. and Bilby, R.E. 1982. Avoidance of suspended sediment by juvenile Coho salmon. North American Journal of Fisheries Management 4: 371-374.

Bleckmann, H. 1985. Perception of water surface waves: how surface waves are used for prey identification, prey localization, and intraspecific communication. In Progress in Sensory Physiology 5. Edited by Ottoson, O. Springer, New York, USA. pp. 147-166. 
Bleckmann, H. 1988. Prey identification and prey localization in surface-feeding fish and fishing spiders. In Sensory Biology of Aquatic Animals. Edited by Atema, J., Fay, R.R., Popper, A.N. and Tavolga, W.N. Springer, New York, USA. pp. 619-641.

Bleckmann, H. 1994. Reception of hydrodynamic stimuli in aquatic and semiaquatic animals. Fisher-Verlag, Stuttgart, Germany.

Bleckmann, H, Mogdans, J. and Dehnhardt, G. 2002. Processing of dipole and more complex hydrodynamic stimuli under still- and running-water conditions. In Sensory Processing in Aquatic Environments. Edited by Collin, S.P. and Marshall, N.J. SpringerVerlag, New York, USA. pp.108-121.

Breithaupt, T. and Tautz, J. 1990. The sensitivity of crayfish mechanoreceptors to hydrodynamic and acoustic stimuli. In Frontiers in Crustacean Neurobiology. Edited by Wiese, K., Krenz, J., Tautz, J. and Mulloney, R.H. Birkhäuser, Basel. pp. 114-120.

Briscoe, A.D. and Chittka, L. 2001. The evolution of color vision in insects. Annual Review of Entomology 46: 471-510.

Brönmark, C. and Hansson, L.A. 2000. Chemical communication in aquatic systems: an introduction. Oikos 88: 103-109.

Budelmann, B.U. 1989. Hydrodynamic receptor systems in invertebrates. In The Mechanosensory Lateral Line. Neurobiology and Evolution. Edited by Coombs, S., Görner, P., Münz, H. Springer, New York, USA. pp. 607-632. 
Buffin-Bélanger, T., Rice, S., Reid, I. and Lancaster, J. 2006. Spatial heterogeneity of nearbed hydraulics above a patch of river gravel. Water Resources Research 42: W04413, doi: 10.1029/2005WR004070.

Busdosh, M., Robilliard, G.A., Talbox, K. and Beehler, C.L. 1982. Chemoreception in an arctic amphipod crustacean: a field study. Journal of Experimental Marine Biology and Ecology 62: 261-269.

Chagnaud, B.P., Bleckmann, H. and Engelmann, J. 2006. Neural responses of goldfish lateral line afferents to vortex motions. The Journal of Experimental Biology 209: 327-342.

Chanson, H. 2009. Current knowledge in hydraulic jumps and related phenomena. A survey of experimental results. European Journal of Mechanics B/ Fluids 28: 191-210.

Chesney, E.J. Jr. 1989. Estimating the food requirements of striped bass larvae Morone saxatilis: effects of light, turbidity and turbulence. Marine Ecology Progress Series 53: 191200.

Church, M. 2012. Mountains and Montane Channels. In Sediment Cascades: An Integrated Approach. Edited by Burt, T. and Allison, R. John-Wiley and Sons, Chichester, UK. pp. 1753.

Collin, S.P. and Marshall, N.J. (eds) Sensory Processing in Aquatic Environments. SpringerVerlag, New York, USA.

Coombs, S. and Janssen, J. 1990. Behavioral and neurophysiological assessment of lateral line sensitivity in the mottled sculpin, Cottus bairdii. Journal of Comparative Physiology A 167: 557-567. 
Crawford, J.D., Jacob, P. and Bénech, V. 1997. Sound production and reproductive ecology of strongly acoustic fish in Africa, Pollimyrus isidori, Mormyridae. Behaviour 134: 677-725.

Crowl, T.A. 1989. Effects of crayfish size, orientation, and movement on the reaction distance of largemouth bass foraging in clear and turbid water. Hydrobiologia 183: 133-140.

Davies-Colley, R.J. and Smith, D.G. 2001. Turbidity, suspended sediment and water clarity: a review. Journal of the American Water Resources Association 37: 1085-1101.

Davies-Colley, R.J. and Close, M.E. 1990. Water colour and clarity of New Zealand rivers under baseflow conditions. New Zealand Journal of Marine and Freshwater Research 24: 357-365.

Death, R.G. 1996. The effect of patch disturbance on stream invertebrate community structure: the influence of disturbance history. Oecologia 108: 567-576.

Death, R.G. 2006. Spatial patterns in benthic invertebrate community structure: products of habitat stability or are they habitat specific? Freshwater Biology 33: 455-467.

Dehnhardt, G., Mauck, B. and Bleckmann, H. 1998. Seal whiskers detect water movements. Nature 394: 235-236.

Derby, C.D. and Atema, J. 1988. Chemoreceptor cells in aquatic invertebrates: Peripheral mechanisms of chemical signal processing in decapod crustaceans. In Sensory Biology of Aquatic Animals. Edited by Atema, J, Fay, R.R, Popper, A.N. and Tavolga, W.N. SpringerVerlag, New York, USA. pp. 365-386. 
Dickenson, M.H. and Lent, C.M. 1984. Feeding behaviour of the medicinal leech, Hirudo medicinalis L. Journal of Comparative Physiology A 154: 449-455.

Dittman, A.H. and Quinn, T.P. 1996. Homing in Pacific salmon: mechanisms and ecological basis. The Journal of Experimental Biology 199: 83-91.

Douglas, R. H. and Hawryshyn, C. W. 1990. Behavioural studies of fish vision: an analysis of visual capabilities. In The visual system of fish. Edited by Douglas, R.H. and Djamgoz, M. Springer, The Netherlands. pp. 373-418.

Effenberger, M., Sailer, G., Townsend, C.R. and Matthaei, C.D. 2006. Local disturbance history and habitat parameters influence the microdistribution of stream invertebrates. Freshwater Biology 51: 312-322.

Enders, E.C., Buffin-Bélanger, T., Boisclair, D. and Roy, A.G. 2005. The feeding behaviour of juvenile Atlantic salmon in relation to turbulent flow. Jounal of Fish Biology 66: 242-253.

Engström-Öst, J. and Candolin, U. 2006. Human-induced water turbidity alters selection on sexual displays in sticklebacks. Behavioral Ecology 18: 393-398.

Fairchild M.P. and Holomuzki, J.R. 2005. Multiple predator effects on microdistributions, survival, and drift of stream hydropsychid caddisflies. Journal of the North American Benthological Society 24: 101-112.

Gibbins, C., Vericat, D. and Batalla, R.J. 2007. When is stream invertebrate drift catastrophic? The role of hydraulics and sediment transport in initiating drift during flood events. Freshwater Biology 52: 2369-2384. 
Giorgi, A.E., Swan, G.A., Zaugg, W.S., Coley, T. and Barila, T.Y. 1988. Susceptibility of Chinook salmon smolts to bypass systems at hydroelectric dams. North American Journal of Fisheries Management 8: 25-29.

Giske, J., Aksnes, D.L. and Fiksen, $\varnothing .1994$. Visual predators, environmental variables and zooplankton mortality risk. Vie et Milieu 44: 1-9.

Gjerløv, C., Hildrew, A.G. and Jones, J.I. 2003. Mobility of stream invertebrates in relation to disturbance and refugia: a test of habitat templet theory. Journal of the North American Benthological Society 22: 207-223.

Hansen, A. and Reutter, K. 2004. Chemosensory systems in fish: Structural, functional and ecological aspects. In The Senses of Fishes: Adaptation for the Reception of Natural Stimuli. Edited by von den Emde, G., Magdans, J. and Kapoor, B.G. Kluwer Academic and SpringerVerlag, Dordrecht, The Netherlands. pp. 55-89.

Haro, A., Odeh, M., Noreika, J. and Castro-Santos, T. 1998. Effect of water acceleration on downstream migratory behavior and passage of Atlantic salmon smolts and juvenile American shad at surface bypasses. Transactions of the American Fisheries Society 127: $118-127$.

Harrison, M.L., Hoover, T.M. and Richardson, J.S. 2006. Agnostic behaviours and movement in the signal crayfish, Pacifastacus leniusculus: can dominance interactions influence crayfish size-class distributions in streams? Canadian Journal of Zoology 84: 1495-1504. 
Hart, D.D, Clark, B.D. and Jasentuliyana A. 1996. Fine-scale field measurement of benthic flow environments inhabited by stream invertebrates. Limnology and Oceanography 41: 297-308.

Hawkins, A.D. and Myrberg, A.A. Jr. 1983. Hearing and sound communication under water. In Bioacoustics, a comparative approach. Edited by Lewis, B. Academic Press, London. pp. 347-405.

Hoover, T.M. and Richardson, J.S. 2010. Does water velocity influence optimal escape behaviors in stream insects? Behavioral Ecology 21: 242-249.

Huntingford, F.A. 1993. Development of behaviour in fish. In Behaviour of Teleost Fishes. Pitcher, T.J. Chapman and Hall, London. pp. 57-84.

James, A.B.W., Dewson, Z.S. and Death, R.G. 2009. The influence of flow reduction on macroinvertebrate drift density and distance in three New Zealand streams. Journal of the North American Benthological Society 28: 220-232.

Janssen, J. 1994. Localization of substrate vibrations by the mottled sculpin (Cottus bairdii). Copeia 1990: 349-355.

Jensen, R.A. and Morse, D.E. 1994. Intraspecific facilitation of larval recruitment gregarious settlement of the polychaete Phragmatopoma californica (Fewkes). Journal of Experimental Marine Biology and Ecology 83: 107-126. 
Kemp, P.S., Anderson, J.J. and Vowles, A.S. 2012. Quantifying behaviour of migratory fish: Application of signal detection theory to fisheries engineering. Ecological Engineering 41: 22-31.

Kemp, P.S., Gessel, M.H., Sandford, B.P., Williams, J.G. 2006. The behaviour of Pacific salmonid smolts during passage over two experimental weirs under light and dark conditions. River Research and Applications 22: 429-440.

Kemp, P.S., Williams, J.G. 2009. Illumination influences the ability of migrating juvenile salmonids to pass a submerged experimental weir. Ecology of Freshwater Fish 18: 297-304.

Kieffer, J.D. and Colgan, P.W. 1992. The role of learning in fish behaviour. Reviews in Fish Biology and Fisheries 2: 125-143.

Kirk, J.T.O. 1994. Light and photosynthesis in aquatic ecosystems (second edition). Cambridge University Press, New York, USA.

Kirk, J.T.O. 1985. Effects of suspensoids (turbidity) on penetration of solar radiation in aquatic ecosystems. Hydrobiologia 125: 195-208.

Koehl, M.A.R. 2006. The fluid mechanics of arthropod sniffing in turbulent odor plumes. Chemical Senses 31:93-105.

Lacey, J.R.W., Neary, V.S., Liao, J.C., Enders, E.C. and Tritico, H. 2012. The IPOS Framework: linking fish swimming performance in altered flows from laboratory experiments to rivers. River Research and Applications 28: 429-443. 
Ladich, F. and Bass, A.H. 2003. Underwater sound generation and acoustic reception in fishes with some notes on frogs. In Sensory processing in aquatic environments. Edited by Collin, S.P. and Marshall, N.J. Springer, New York, USA. pp. 173-193.

Lagardére, J.P., Bégout, M.L., Lafaye, J.Y and Villotte, J.P. 1994. Influence of windproduced noise on orientation in the sole (Solea solea). Canadian Journal of Fisheries and Aquatic Science 51: 1258-1264.

Lamouroux, N., Mérigoux, S., Capra, H., Dolédec, S., Jowett, I.G. and Statzner, B. 2010. The generality of abundance-environment relationships in microhabitats: A comment on Lancaster and Downes (2009). River Research and Applications 26: 915-920.

Lancaster, J. and Downes, B.J. 2011. Linking the hydraulic world of individual organisms to ecological processes: putting ecology into ecohydraulics. River Research and Applications 26: 385-403.

Lancaster, J. and Downes, B.J. 2013. Aquatic Entomology. Oxford University Press, UK.

Lancaster J. and Hildew, A.G. 1993. Flow refugia and the microdistribution of lotic macroinvertebrates. Journal of the North American Benthological Society 12: 385-393.

Leis, J.M., Carson-Ewart, B.M., Cato, D.H. 2002. Sound detection in situ by the larvae of a coral reef damselfish. Pomacentridae 232: 259-268.

Leis, J.M., Carson-Ewart, B.M., Hay, A.C. and Cato, D.H. 2003. Coral-reef sound enable nocturnal navigation by some reef-fish larvae in some places and at some times. 63: 724737. 
Lima, S.L. and Zollner, P.A. 1996. Towards a behavioral ecology of ecological landscapes. Trends in Ecology and Evolution 11: 131-135.

Liao, J.C., Beal, D.N., Lauder, G.V. and Triantafyllou, M.S. 2003. The Karman gait: novel body kinematics of rainbow trout swimming in a vortex street. Journal of Experimental Biology 206: 1059-1073.

Lloyd, D.S., Koenings, J.P. and La Perriere, J.D. 1987. Effects of turbidity in fresh waters of Alaska. North American Journal of Fisheries Management 7: 18-33.

Losey, G.S., Cronin, T.W., Goldsmith, T.H., Hyde, D., Marshall, N.J. and McFarland, W.N. 2005. The UV visual world of fishes: a review. Journal of Fish Biology 54: 921-943.

Lugli, M., Pavan, G. and Torricelli, P. 1996. The importance of breeding vocalizations for mate attraction in a freshwater goby with composite sound repertoire. Ethology, Ecology, Evolution 8:343-351

Lugli, M. and Fine, M.L. 2003. Acoustic communication in two freshwater gobies: Ambient noise and short-range propagation in shallow streams. Journal of the Acoustical Society of America 114: 512-521.

Lugli, M., Yan, H.Y. and Fine, M.L. 2003. Acoustic communication in two freshwater gobies: the relationship between ambient noise, hearing thresholds and sound spectrum. Journal of Comparative Physiology A 189: 309-320.

Lugli, M. and Fine, M.L. 2007. Stream ambient noise, spectrum and propagation of sounds in the goby Padogobius martensii: Sound pressure and particle velocity. Journal of the Acoustical Society of America 122:2881-2892. 
Lythgoe, J.N. 1988. Light and vision in the aquatic environment. In Sensory Biology of Aquatic Animals. Edited by Atema, J., Fay, R.R., Popper, A.N, Tavolga, W.N. Springer Verlag, New York, USA. pp. 57-82.

Madliger, C.L. 2012. Toward improved conservation management: a consideration of sensory ecology. Biodiversity and Conservation 21: 3277-3286.

Mann, D.A and Lobel, P.S. 1997. Propagation of damselfish (Pomacentridae) courtship sounds. Journal of the Acoustical Society of America 101: 3783-3791.

Martin, A.E, Hoover, T.M. and Richardson, J.S. 2013. Modeling the role of stage-structured agonistic interactions in ontogenetic habitat shifts. Behavioral Ecology 24: 355-365.

Matthaei, C.D., Arbuckle, C.J. and Townsend, C.R. 2000. Stable surface stones as refugia for invertebrates during disturbance in a New Zealand stream. Journal of the North American Benthological Society 19: 82-93.

McDonald, C.G., Reimchen, T.E. and Hawryshyn, C.W. 1995. Nuptial colour loss and signal masking in Gasterosteus: An analysis using video imaging. Behaviour 132: 963-977.

McDonald, C.G. and Hawryshyn, C.W. 1995. Intraspecific variation of spectral sensitivity in threespine stickleback (Gasterosteus aculeatus) from different photic regimes. Journal of Comparative Physiology A 176: 255-260.

Miner, J. and Stein, R.A. 1993. Interactive influence of turbidity and light on larval bluegill (Lepomis macrochirus) foraging. Canadian Journal of Fisheries and Aquatic Sciences 50: 781-788. 
Montgomery, D.R. and Buffington, J.M. 1997. Channel-reach morphology in mountain drainage basins. Geological Society of America Bulletin 109: 596-611.

Moore, P.A. and Grills, J.L. 1999. Chemical orientation to food by the crayfish Orconectes rusticus: influence of hydrodynamics. Animal Behaviour 58: 953-963.

Nestler, J.M., Pompeu, P.S., Goodwin, R.A., Smith, D.L., Silva, L.G.M., Baigún, C.R.M. and Oldani, N.O. 2012. The river machine: a template for fish movement and habitat, fluvial geomorphology, fluid dynamics and biogeochemical cycling. River Research and Applications 28: 490-503.

Nikora, V., Aberle, J., Biggs, J.F., Jowett, I.G. and Sykes, J.R.E. 2003. Effects of fish size, time-to-fatigue and turbulence on swimming performance: a case study of Galaxias maculatus. Journal of Fish Biology 63: 1365-1382.

Nikora, V., Goring, D., McEwan, I. and Griffiths, G. 2001. Spatially averaged open-channel flow over rough bed. Journal of Hydraulic Engineering 127: 123-133.

Nikora, V. 2010. Hydrodynamics of aquatic ecosystems: An interface between ecology, biomechanics and environmental fluid mechanics. River Research and Applications 26: 367384.

Norton, G.V. and Novarini, J.C. 2001. On the relative role of sea-surface roughness and bubble plumes in shallow-water propagation in the low-kilohertz region. Journal of the Acoustical Society of America 110: 2946-2955. 
O'Connel-Rodwell, C.E. 2007. Keeping an "ear" to the ground: seismic communication in elephants. Physiology 22: 287-294.

Officer, C.B. 1958. Introduction to the theory of sound transmission with application to the ocean. McGraw-Hill, New York, USA.

Oldmeadow, D.F., Lancaster, J. and Rice, S.P. 2010. Drift and settlement of stream insects in a complex hydraulic environment. Freshwater Biology 55: 1020-1035.

Palmer, M.A., Ambrose, R.F. and Poff, N.L. 1997. Ecological theory and community restoration ecology. Restoration Ecology 5: 291-300.

Pawlik, J.R. and Butman, C.A. 1993. Settlement of a marine tube worms as a function of current velocity: interacting effects of hydrodynamics and behavior. Limnology and Oceanography 38: 1730-1740.

Peckarsky, B.L. and Wilcox, R.D. 1989. Stonefly nymphs use hydrodynamic cues to discriminate between prey. Oecologia 79: 265-270.

Pijanowski, B.C., Villanueva-Rivera, L.J., Dumyahn, S.L., Farina, A., Krause, B.L., Napoletano, B.M., Gage, S.H. and Pieretti, N. 2011. Soundscape ecology: The science of sound in the landscape. BioScience 61: 203-216.

Pitcher, T.J. (ed) 1993. Behaviour of teleost fishes, $2^{\text {nd }}$ edition. Chapman and Hall, London, UK. 
Plachta, D., Hanke, W. and Bleckmann, H. 2003. A hydrodynamic topographic map and two hydrodynamic sub-systems in a vertebrate brain. Journal of Experimental Biology 206: 3479-3486.

Popper, A.N., Fewtrell, J., Smith, M.E. and McCauley, R.D. 2003. Anthropogenic sound: Effects on the behavior and physiology of fishes. Marine Technology Society Journal 37: 3540.

Reiskind, M.H., Grrene, K.L. and Lounibos, L.P. 2009. Leaf species identity and combination affect performance and oviposition choice of two container mosquito species. Ecological Entomology 34: 447-456.

Rice, S.P., Lancaster, J. and Kemp, P. 2010. Experimentation at the interface of fluvial geomorphology, stream ecology and hydraulic engineering and the development of an effective, interdisciplinary river science. Earth Surface Processes and Landforms 35: 64-77.

Rice, S.P., Buffin-Bélanger, T., Lancaster, J. and Reid, I. 2008. Movements of a macroinvertebrate (Potamophylax latipennis) across a gravel bed substrate: effects of local hydraulics and micro-topography under increasing discharge. In Gravel-bed Rivers: From Process Understanding to River Restoration. Edited by Habersack, H., Hoey, T., Piegay, H. and Rinaldi, M. Elsevier, Amsterdam, The Netherlands. pp. 637-660.

Rickenmann, D. and McArdell, B.W. 2007. Continuous measurement of sediment transport in the Erlenbach stream using piezoelectric bedload impact sensors. Earth Surface Processes and Landforms 32: 1362-1378. 
Roberts, P.J.W. and Webster, D.R. 2002. Turbulent diffusion. In Environmental Fluid Mechanics - Theories and Applications. Edited by Shen, H., Cheng, A., Wang, K.-H., Teng, M. and Liu, C. ASCE Press, Virginia, USA.

Rogers, P.H. and Cox, M. 1988. Underwater sound as a biological stimulus. In Sensory Biology of Aquatic Animals. Edited by Atema, J., Fay, R.R., Popper, A.N. and Tavolga, W.N. Springer, New York, USA. pp. 131-149.

Rowe, D.K. and Dean, T.L. 1998. Effects of turbidity on the feeding ability of the juvenile migrant stage of six New Zealand freshwater fish species. New Zealand Journal of Marine and Freshwater Research 32: 21-29.

Roy, A.G., Buffin-Belanger, T., Lamarre, H. and Kirkbride, A.D. 2004. Size, shape and dynamics of large-scale turbulent flow structures in a gravel-bed river. Journal of Fluid Mechanics 500: 1-27.

Schlaepfer, M.A., Runge, M.C. and Sherman, P.W. 2002. Ecological and evolutionary traps. TRENDS in Ecology and Evolution 17: 474-480.

Scholz, K. and Ladich, F. 2006. Sound production, hearing and possible interception under ambient noise conditions in the topmouth minnow Pseudorasbora parva. Journal of Fish Biology 69: 892-906.

Sharma, S., Coombs, S., Patton, P. and Burt de Perera, T. 2009. The function of wallfollowing behaviors in the Mexican blind cavefish and a sighted relative, the Mexican tetra (Astyanax). Journal of Comparative Physiology A 195: 225-240. 
Sigler, J.W., Bjornn, T.C. and Everest, F.H. 1984. Effects of chronic turbidity on density and growth of Steelheads and Coho salmon. Transactions of the American Fisheries Society 113: $142-150$

Simpson, S.D., Meekan, M.G., Jeffs, A., Montgomery, J.C. and McCauley, R.D. 2008. Settlement-stage coral reef fish prefer the higher-frequency invertebrate-generated audible component of reef noise. Animal Behaviour 75: 1861-1868.

Stebbing, P.D., Watson, G.J., Bentley, M.G., Fraser, D., Jennings, R., Rushton, S.P. and Sibley, P.J. 2004. Evaluation of the capacity of pheromones for control of invasive nonnative crayfish. English Nature Research Reports 578, Peterborough, UK.

Tachet, H. 1977. Vibrations and predatory behaviours of Plectrocnemia conspersa larvae (Trichoptera). Zeitschrift für Tierpsychologie 45: 61-74.

Tamburri, M.N. and Barry, J.P. 1999. Adaptations for scavenging by three diverse bathyla species, Eptatretus stouti, Neptunea amianta and Orchomene obtusus. Deep-Sea Research | 46: 2079-2093.

Tautz, J. and Sandeman, D.C. 1980. The detection of waterborne vibration by sensory hairs on the chelae of the crayfish. Journal of Experimental Biology 88: 351-356.

Thorp, W.H. and Crisp, D.J. 1947. Studies on plastron respiration. III. The orientation responses of Aphelocheirus (Hemiptera, Aphelocheiridae (Naucoridae)) in relation to plastron respiration; together with an account of specialized pressure receptors in aquatic insects. Journal of Experimental Biology 24: 310-328. 
Tikkanen, P., Huhta, A. and Muotka, T. 2000. Determinants of substrate selection in lotic mayfly larvae: is cryptic coloration important? Archiv für Hydrobiologie A 148: 45-57.

Tolimieri, N., Jeffs, A. and Montgomery, J.C. 2000. Ambient sound as a cue for navigation by the pelagic larvae of reef fishes. Marine Ecology Progress Series 207: 219-224.

Tolimieri, N., Haine, O., Jeffs, A., McCauley, R.D. and Montgomery, J.C. 2004. Directional orientation of pomacentrid larvae to ambient reef sound. Coral Reefs 23: 184-191.

Tonolla, D., Acũna, V., Lorang, M.S., Heutschi, K. and Tockner, K.. 2010. A field-based investigation to examine underwater soundscapes of five common river habitats. Hydrological Processes 24: 3146-3156.

Tonolla, D., Lorang, M.S., Heutschi, K. and Tockner, K. 2009. A flume experiment to examine underwater sound generation by flowing water. Aquatic Sciences 71: 449-462.

Turesson, H. and Brönmark, C. 2007. Predator-prey encounter rates in freshwater piscivores effects of prey density and water transparency. Oecologia 153: 281-290.

Urick, R.J. 1983. Principles of underwater sound. McGraw-Hill, New York, USA.

Utne-Palm, A.C. 2002. Visual feeding of fish in a turbid environment: physical and behavioural aspects. Marine and Freshwater Behavioural Physiology 35: 111-128.

Van Dam, A.R. and Walton, W.E. 2008. The effect of predatory fish exudates on the oviposition behaviour of three mosquito species: Culex quinquefasciatus, Aedes aegypti and Culex tarsalis. Medical and Veterinary Entomology 22: 399-404. 
van de Hulst, H.C. 1957. Light scattering by small particles. John Wiley and Sons, New York, USA.

von Campenhausen, C., Riess, I. and Weissert, R. 1981. Detection of stationary objects in the blind cave fish Anoptichthys jordani (Characidae). Journal of Comparative Physiology A 143: $369-374$.

Walmsley, R.D., Butty, D.M., van der Piepen, H. and Grobler, D. 1980. Light penetration and the inter-relationships between optical parameters in a turbid subtropical impoundment. Hydrobiologia 70: 145-157.

Webster D.R. and Weissburg, M.J. 2009. The hydrodynamics of chemical cues among aquatic organisms. Annual Review of Fluid Mechanics 41: 73-90.

Weissburg, M.J. and Zimmer-Faust, R.K. 1993. Life and death in moving fluids: hydrodynamic effects on chemosensory-mediated predation. Ecology 74: 1428-1443.

Weissburg, M.J. and Zimmer-Faust, R.K. 1994. Odor plumes and how blue crabs use them in finding prey. Journal of Experimental Biology 197:349-375.

Whang, A. and Janssen, J. 1994. Sound production through the substrate during reproduction in the mottled sculpin, Cottus bairdii (Cottidae). Environmental Biology of Fishes 40: 141-148.

Wiese, K. 1976. Mechanoreceptors for near-field water displacements in crayfish. Journal of Neurophysiology 39: 816-833. 
Wilkes, M.A., maddock, I., Visser, F. and Acreman, M.C. 2013. Incorporating hydrodynamics into ecohydraulics: The role of turbulence in the swimming performance and habitat selection of stream-dwelling fish. In Ecohydraulics: An Integrated Approach. Edited by Maddock, I., Harby, A., Kemp, P. and Wood, P. Wiley, Chichester, UK. pp. 9-30.

Wisenden, B.D. and Millard, M.C. 2001. Aquatic flatworms use chemical cues from injured conspecifics to assess predation risk and to associate risk with novel cues. Animal Behaviour 62: 761-766.

Witherington, B.E. and Martin, R.E. 1996. Understanding, assessing and resolving light pollution problems on sea turtle nesting beaches. FMRI technical report TR-2, Florida Marine Research Institute.

Witzgall, P., Kirsch, P. and Cork, A. 2010. Sex pheromones and their impact on pest management. Journal of Chemical Ecology 36: 80-100.

Wolf, M.C., Martin III, A.L., Simon, J.L., Bergner, J.L. and Moore, P.A. 2009. Chemosensory signals in stream habitats: implications for ecological interactions. Journal of the North American Benthological Society 28: 560-571.

Wrege, P.H., Rowland, E.D., Thompson, B.G. and Batruch, N. 2010. Use of acoustic tools to reveal otherwise cryptic responses of forest elephants to oil exploration. Conservation Biology 24: 1578-1585.

Wysocki, L.E. and Ladich, F. 2005. Hearing in fishes under noise conditions. Journal of the Association for Research in Otolaryngology 6: 28-36. 
Wysocki, L.E., Amoser, S. and Ladich, F. 2007. Diversity in ambient noise in European freshwater habitats: Noise levels, spectral profiles, and impact on fishes. Journal of the Acoustic Society of America 121: 2559-2566.

Zimmer, R.K. and Butman, C.A. 2000. Chemical signalling processes in the marine environment. Biological Bulletin 198: 168-187. 
Tables:

Table 1: What controls the propagation of sensory information in GBR?

\begin{tabular}{|c|l|l|}
\hline Sense & \multicolumn{1}{|c|}{ Phenomena received } & \multicolumn{1}{|c|}{ Abiotic control } \\
\hline Visual & $\begin{array}{l}\text { Presence of light, specific light spectra } \\
\text { including UV, polarized light }\end{array}$ & $\begin{array}{l}\text { Turbidity, topography, solar geometry, } \\
\text { shading }\end{array}$ \\
\hline Acoustic & $\begin{array}{l}\text { Particle and pressure waves using } \\
\text { hairs and gas-filled chambers, } \\
\text { unaffected by flow direction }\end{array}$ & $\begin{array}{l}\text { Plunging water, bubbles, water depth } \\
\text { due to the "cut-off phenomenon", bed } \\
\text { roughness }\end{array}$ \\
\hline Hydrodynamic & $\begin{array}{l}\text { Deflection of spatially-distributed } \\
\text { hairs by flowing water, sometimes } \\
\text { also pressure differences }\end{array}$ & Flow direction, turbulence \\
\hline Vibrations & $\begin{array}{l}\text { Pressure and particle waves travelling } \\
\text { sub-surface }\end{array}$ & Substrate structure and composition \\
\hline Chemical & $\begin{array}{l}\text { Biochemicals (both fluid and those } \\
\text { attached to solid objects) }\end{array}$ & Flow direction, turbulence \\
\hline
\end{tabular}




\section{Figures:}

Figure 1: Flow diagram showing the stages between production and perception of sensory signals. Modified from Zimmer and Butmann (2000). Used with permission from the Marine Biological Laboratory.

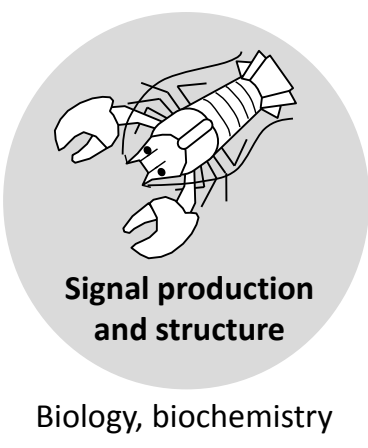

Biology, biochemistry

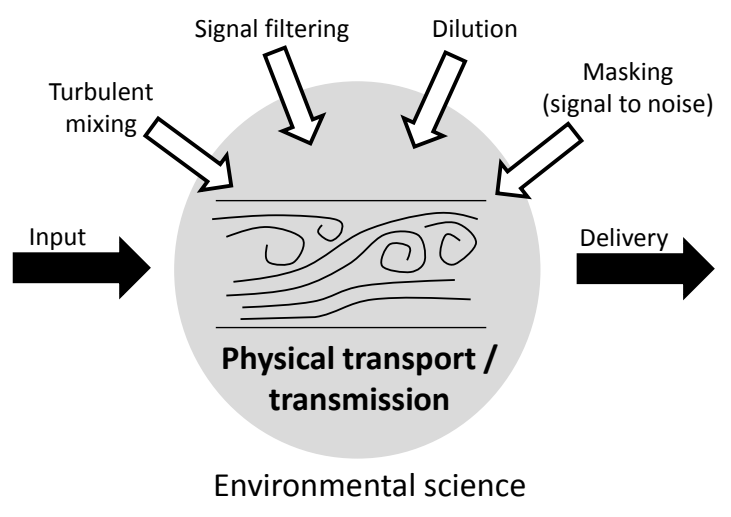

Behavioural (or physiological) response

Biology, ecology 
Figure 2: Diagrammatic representation of the environmental controls on the transmission of acoustic signals in gravel-bed rivers. Note the vertical scale is exaggerated.

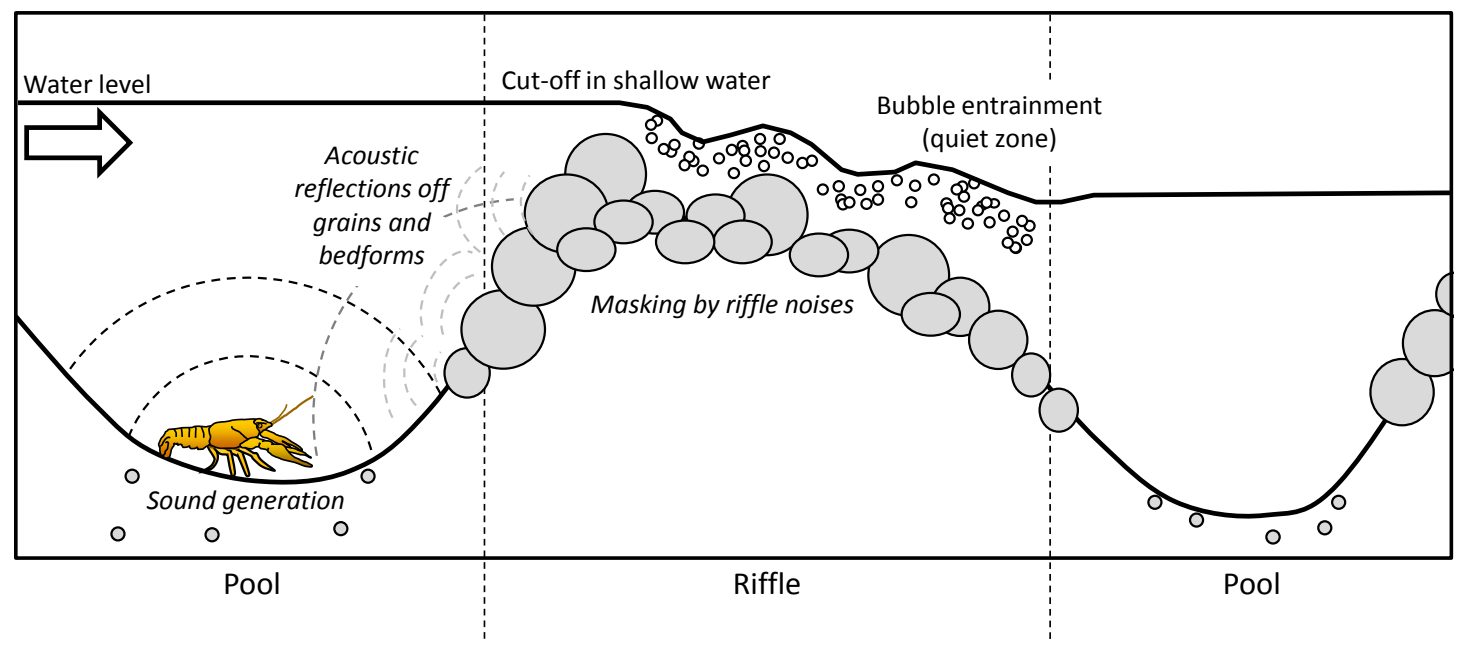


Figure 3: The scales of turbulence that control waterborne sensory information, covering at least 5 orders of magnitude. In this illustration, the chemical scent of fish urine is received by the chemo-receptive hairs on a crayfish's antenna. Note the scale represents the spatial scale of the phenomena, not the distance covered. For example, an odour plume may only travel a few centimetres but its transmission will be partially controlled by turbulent features generated at macro-scale (10s m). Because the initial excretion undergoes degrees of mixing across all scales, the chemical signal received by the crayfish is likely to be substantially different from that originally generated by the fish, in terms of concentration, time duration and spatial extent.

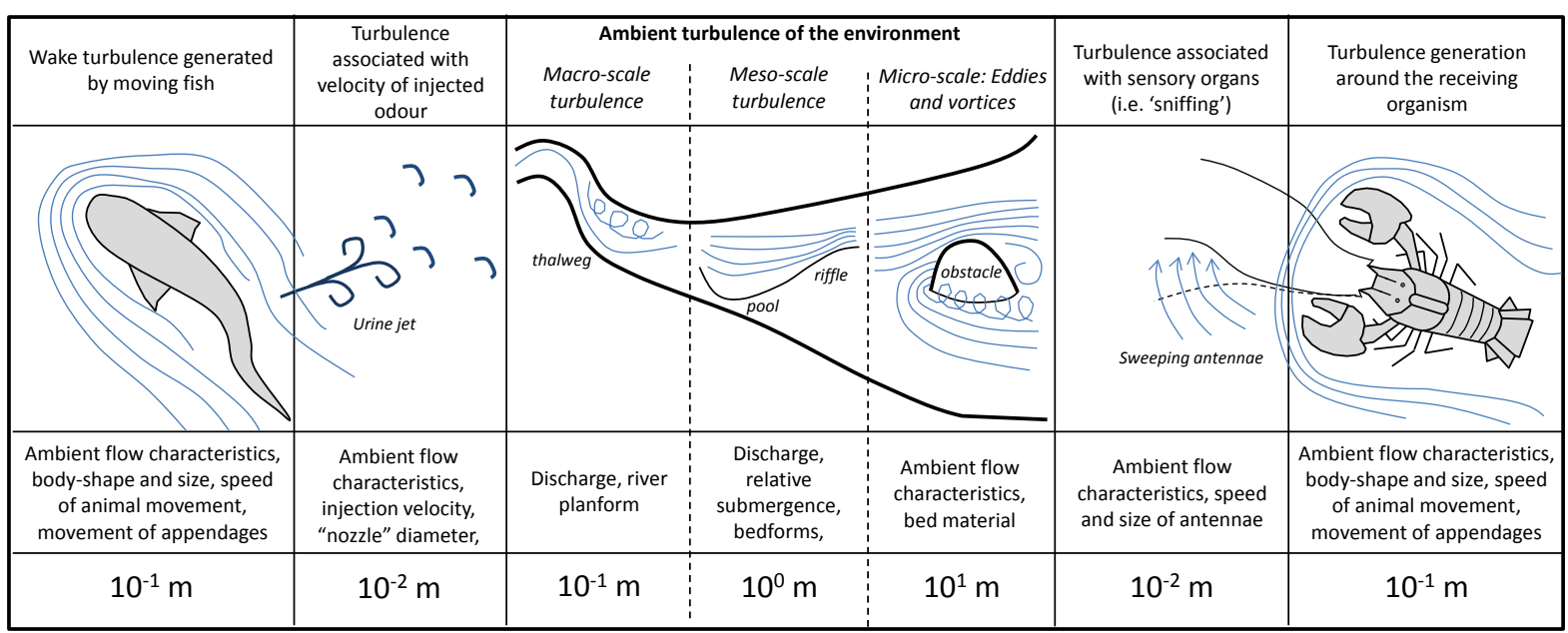


Figure 4: Animals are continuously confronted with new situations due to the patchiness of fluvial habitats in space and their variability in time. Animals receive biotic and abiotic sensory information which they must interpret to gain information about their surroundings. This information is transmitted, transformed, masked and mixed by the ambient environment. Of particular importance are the flow velocity $(v)$, flow depth $(y)$, sediment roughness $(H)$, relative submergence $h=y / H$ and Coherent Flow Structures (CFS). Animals must interpret the resultant information and use it to make decisions, such as whether to stay or leave an area or whether to hide from predators or hunt prey.

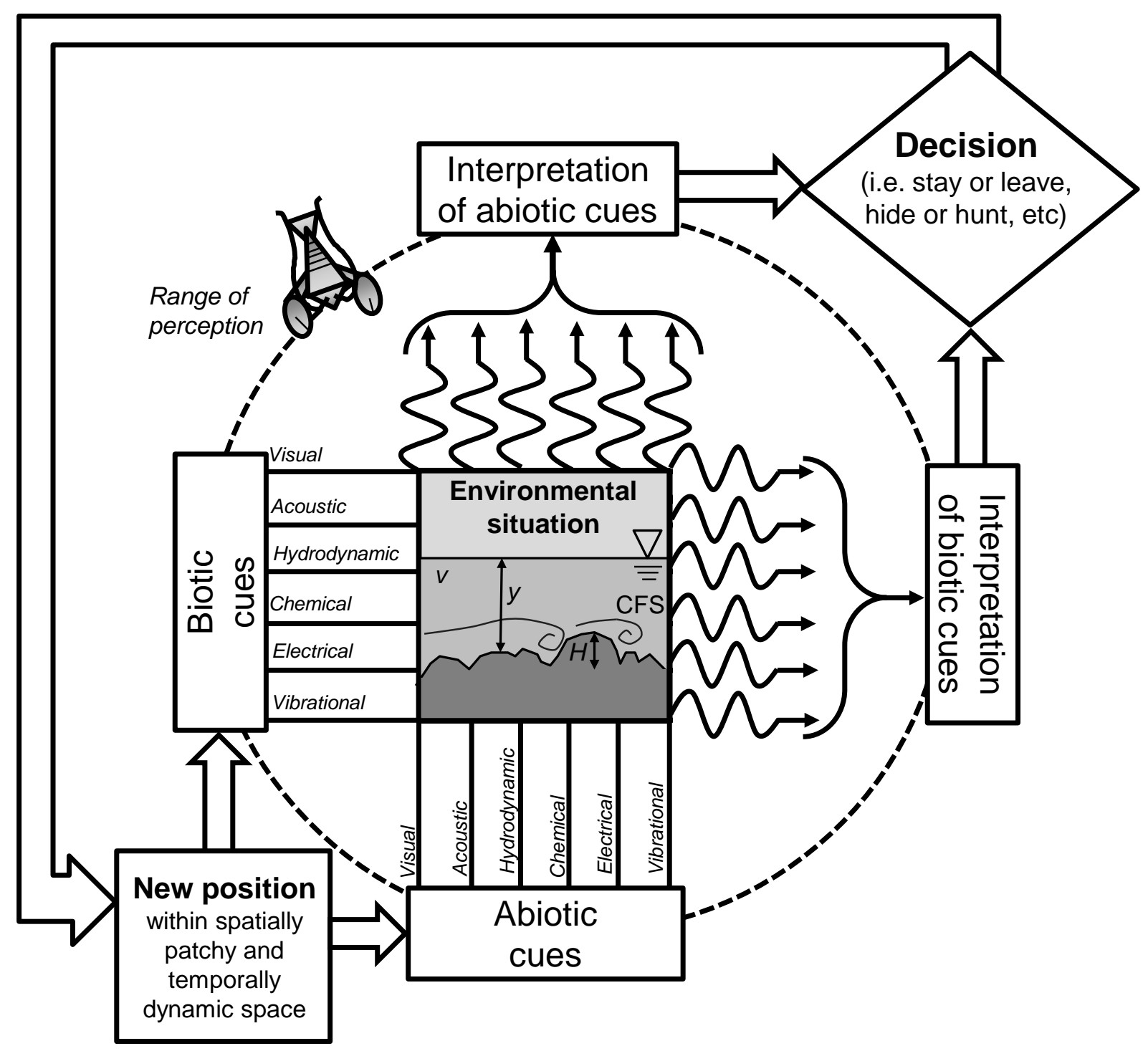

